\title{
Perceived Social Support and Its Association with Depression Among Patients Infected with HIV: A Hospital Based Study in Jos, Nigeria
}

\author{
Halima Mwuese Sule ${ }^{1, *}$, Mark Davou Gyang ${ }^{1}$, Michael Terkura Agbir², \\ Kingsley Mayowa Okonoda ${ }^{3}$ \\ ${ }^{1}$ Department of Family Medicine, University of Jos, Jos University Teaching Hospital, Jos, Nigeria \\ ${ }^{2}$ Department of Psychiatry, Benue State University, Makurdi, Nigeria \\ ${ }^{3}$ Department of Psychiatry, University of Jos, Jos University Teaching Hospital, Jos, Nigeria
}

Email address:

haltsav@yahoo.com (H. M. Sule)

${ }^{*}$ Corresponding author

\section{To cite this article:}

Halima Mwuese Sule, Mark Davou Gyang, Michael Terkura Agbir, Kingsley Mayowa Okonoda. Perceived Social Support and Its Association with Depression Among Patients Infected with HIV: A Hospital Based Study in Jos, Nigeria. International Journal of HIV/AIDS Prevention, Education and Behavioural Science. Vol. 5, No. 1, 2019, pp. 68-75. doi: 10.11648/j.ijhpebs.20190501.19

Received: April 20, 2019; Accepted: May 28, 2019; Published: June 10, 2019

\begin{abstract}
The chronicity of HIV infection predisposes the infected to mental health problems such as depression that demand a need for social support. The perception of social support is key to its beneficial effects. This study aimed to assess the level of perceived social support and its association with depression among patients infected with HIV in a hospital in Jos, Nigeria. In a cross-sectional study, 386 participants selected by systematic random sampling were interviewed to obtain their sociodemographic information, and they were assessed for perceived social support and depression using the Multidimensional Scale of Perceived Social Support and the PHQ-9 Questionnaire respectively. Data was analysed using Epi info version 7. Half the proportion of participants $(50.5 \%)$ had a moderate level of perceived social support, while $39.9 \%$ and $9.6 \%$ had low and high levels of perceived social support respectively. Female gender, age $\geq 45$ years, absence of a history of being affiliated with a HIV support group, low educational status, low income, unemployment and shorter duration of known HIV diagnosis were negatively associated with lower levels of perceived social support. The prevalence of depression was $32.6 \%$, and lower levels of perceived social support were significantly associated with depression. The results suggest gaps in the social support needs of the participants. This highlights a need for interventions aimed at improving the perception of social support among people living with HIV. Further studies are needed to identify those unmet needs so as to device strategies to address them in order to close the gaps in perception and enhance mental health in HIV care.
\end{abstract}

Keywords: Perceived Social Support, Depression, HIV

\section{Introduction}

Millions of people worldwide are living with human immunodeficiency virus (HIV) infection, with a current global statistics report of 36.9 million in 2017, with subSaharan Africa contributing approximately two-thirds of this figure [1]. Globally, 35.4 million people have died from HIV-related illnesses since the onset of the epidemic, with the greater proportion of deaths occurring in the pre antiretroviral therapy (ART) era. The use of ART has majorly contributed to increasing the lifespan of persons infected with the virus; however ART alone does not take care of the psychosocial challenges associated with being HIV infected. People living with HIV/AIDS (PLWHA) have a higher risk for mental health conditions. Research has shown that depression is the most prevalent mental health condition occurring in PLWHA, with pooled prevalence estimate rates of up to $32 \%$ in sub-Saharan Africa, and rates greater than $60 \%$ reported in some other parts of the world [2-4]. Depression has been reported to occur up to five times more commonly in HIV infected persons than in non-infected persons. Depression ranks top among the diseases causing 
disability worldwide, and it is also responsible for a significant contribution to the global burden of disease [5]. The existence of depression in PLWHA increases the overall burden of disease and worsens the outcome. To improve mental health and HIV care outcomes, the psychosocial needs of PLWHA need to be identified and addressed to complement the benefits of ART.

Due to the nature of HIV disease, from the time of being diagnosed HIV positive, most PLWHA are exposed to various stressors that could impact their mental health and increase their risk for depression, such as dealing with the initial diagnosis, confronting disclosure issues, coping with disease symptom burden and complications, concerns about well-being, frequent clinic attendance/burden of taking pills, stigma and discrimination, job loss, death of loved ones, and over time, the chronicity of HIV disease accorded by ART, demanding long term care and support. All of the aforementioned stressful situations may be alleviated by social support, and if social support is low or lacking, the mental well-being of PLWHA is affected negatively [6].

Social support refers to the various types of assistance or help that people feel, notice or receive from others (family, friends and community) and is classified as: (i) Emotional support - non-tangible assistance that makes an individual feel loved, respected and cared for, boosts sense of self-worth e.g. talking over a problem, providing encouragement/positive feedback; (ii) Instrumental support tangible assistance e.g. provision of transportation or money, help with child care/housekeeping; (iii) Informational support - help provided in the form of information. Social support may be actual or perceived. While actual social support is available or provided support, perceived social support is support that an individual believes to be available, regardless of whether the support is actually available [7]. The provision or availability of actual social support differs from perceived social support, with perceived social support being more significant than actual social support in relation to health behaviours [6]. Results of a US based study comparing the effect of perceived and actual social support on the mental health of HIV-positive persons concluded that perceived social support was more significantly predictive of better mental health outcome than actual social support [8].

Lack of social support has been implicated as a risk factor for depression in various conditions [9-12]. Various instruments currently exist for the measurement/assessment of social support. One of such tools is the Multidimensional Scale of Perceived Social Support (MSPSS) [13]. It has been used widely across many studies, and translated into many languages. It has been shown to be reliable and have good validity [13].

Studies in PLWHA across various geographical regions of the world have identified social support, particularly perceived social support to have a buffering effect against stress related factors that predispose to depression and other conditions that negatively affect psychological well-being [14].

Researchers who examined the role of perceived social support in improving the lives of PLWHA, suggested a buffering effect of social support against stress related factors such as depression, hopelessness, physical distress, disclosure to partners and psychological well-being [8, 14]. Other researchers have recorded an association between high levels of social support and the absence or reduction of depression $[15,16]$.

Just as PLWHA in other parts of the world, HIV-infected patients in Nigeria are also exposed to many stress related issues linked to having a diagnosis of HIV, which could tip them into clinical depression. Reports from studies in PLWHA from other parts of the world have identified social support as a buffer to stress. Since perception of social support in PLWHA may vary across geographical regions, assessing perceived social support and its association with depression in a local population of PLWHA would create the awareness needed to incorporate and optimize the use of available social support into HIV care, so as to improve patient care and outcome. This study aimed at assessing perceived social support and determining its association with depression among a local population of patients receiving ART in the adult clinic of APIN, JUTH, in Nigeria.

\section{Methodology}

\subsection{Background of the Study Area}

The study was carried out in the Adult ART Clinic of AIDS Prevention Initiative in Nigeria (APIN) Centre, Jos University Teaching Hospital (JUTH), Plateau State, northcentral Nigeria. The clinic is one of the largest HIV care centres in the country with a cumulative patient load of over 26,000 since inception in 2002 till date, serving Plateau and neighbouring states of Bauchi, Benue, Kaduna, Nassarawa and Taraba. The APIN Centre also runs a Paediatric ART Clinic and a Prevention of Mother-to-Child Transmission Clinic providing care to children and pregnant women. Plateau State has a population of 3.2 million people, with an estimated $1.6 \%$ of them living with HIV/ AIDS $[17,18]$.

This was a hospital based, descriptive cross-sectional study to assess perceived social support in PLWHA and determine its association with depression. The study population was made up of adult male and female patients, enrolled at the adult ART clinic of APIN, JUTH. The study population comprised of all patients enrolled in the Adult ART Clinic, and receiving antiretroviral therapy for at least 1 year. A sample size of 386 was used for the study, determined by the formula for minimum sample size estimation in a cross sectional study: $\mathrm{n}=\mathrm{z}^{2} \mathrm{pq} / \mathrm{d}^{2}$, and participants were selected by systematic random sampling [19].

\subsubsection{Inclusion and Exclusion Criteria}

All consenting patients aged 18 years or older, enrolled for care in the Adult ART Clinic, who had been receiving antiretroviral therapy for the preceding 1 year were eligible while patients who were very ill or on treatment for a psychiatric condition were excluded.

\subsection{Collection of Data}


Data was obtained using an interviewer administered questionnaire made up of the following 3 sections:

\subsubsection{Sociodemographic and Clinical Information}

This included age, sex, marital status, religion, educational status, monthly income, history of affiliation with a support group, known duration of HIV infection, most recent CD4 count level, recent viral load, ART regimen, and adherence percentage.

\subsubsection{Perceived Social Support}

The MSPSS questionnaire was used to measure participants' perception of support from family, friends, and significant other [13]. The MSPSS consisting of 12 items, each with 7 possible responses on a 7 point scale, scored 1-7 as follows: 1 = very strongly disagree; $2=$ strongly disagree; $3=$ mildly disagree; $4=$ neutral; $5=$ mildly agree; $6=$ strongly agree; $7=$ very strongly agree]. The total score was the sum of the scores for all 12 items. The possible range for total score was $12-84$, graded as: $12-48=$ low perceived social support; 49 - 68 = moderate perceived social support; $69-84=$ high perceived social support.

\subsubsection{Depression}

The PHQ-9 Questionnaire was used to assess the patients for depression with 9 questions, each with 4 possible options as responses [20]. The scores awarded for each of the 4 responses were as follows: 'not at all'-0; 'several days'-1; 'more than half the days'- 2; 'nearly every day' -3 . The sum of the scores graded depression as follows: $0-4=$ minimal or none; $5-9=$ mild; 10-14=moderate; $15-19=$ moderately severe; $20-27=$ severe. Participants with scores of $\leq 4$ were categorised not to have depression while all those who scored $>4$ were categorized to have depression. Grading also identified those patients who required treatment/ referral.

\subsection{Ethical Consideration}

Ethical approval for the study was obtained from the JUTH Ethical Committee and permission to carry out the study and use secondary data was sought from APIN management, JUTH and Abuja offices prior to commencement of the study. Informed consent was obtained from each participant, and their information was kept confidential and anonymous.

\subsection{Data Analysis}

All data obtained was coded and analysed using Epi info statistical software version 7 (CDC Atlanta, GA, USA). Categorical variables were expressed as frequencies and percentages while continuous variables were expressed as means \pm standard deviation. Chi square was used to compare differences in proportions. Analysis of variance (ANOVA) was used to assess differences between means. A confidence level of $95 \%$ was used for the study and a $\mathrm{P}$ value of $<0.5$ was considered statistically significant.

\section{Results}

\subsection{Sociodemographic and Clinical Characteristics}

Three hundred and eighty-six participants were recruited for the study. Eighty-seven (22.5\%) were male and 299 $(77.5 \%)$ were female. The mean age was $45 \pm 10.3$ years. Majority of them were urban dwellers $(68.7 \%)$ and practised Christianity (82\%). More than half of them (56.7\%) were educated beyond primary level of education and employed including self- employment (56.7\%), however $68.1 \%$ of them had a monthly income of less than N18,000. The mean known duration of HIV infection was $10.4 \pm 4.0$ years, and $20 \%$ of the total population had a history of being affiliated with a HIV support group. A large proportion of the participants $(82 \%)$ had an adherence level of equal to or greater than $95 \%$. Ninety-two percent of the participants had a viral load level of less than 1000 copies $/ \mathrm{ml}$, while less than half of the patients $(46.4 \%)$ had a CD4 count level of $\geq 500$ cells $/ \mathrm{mm}^{3}$. The commonest ART regimen was zidovudinelamivudine-nevirapine (45.1\%), followed by efavirenzcontaining fixed dose combination regimens (38.1\%). Fiftysix $(14.5 \%)$ of the participants were on second-line regimens. Of the 386 patients, 126 (32.6\%) were assessed to have some degree of depression ranging from mild to severe. Table 1.

\subsection{Perceived Social Support in Study Participants}

Of the 386 patients assessed, the overall mean total perceived social support score was $48.5 \pm 14.7$ (males $=53.2$ \pm 13.6 , female $=47.0 \pm 14.7$ ). Approximately half of the population $(50.5 \%)$ had a moderate level of perceived social support while $39.9 \%$ and $9.6 \%$ had low and high levels of perceived social support respectively. Perceived social support level and mean scores were significantly associated with gender, age, history of affiliation with a support group, known duration of HIV infection, monthly income, educational and employment status ( $p$ value $=0.001,0.04,<$ $0.00001,<0.00001,0.0008,0.03$ and 0.009 respectively). Religion, marital status, place of domicile, adherence percentage, CD4 count and viral load level did not show any significant association with perceived social support levels. Tables $2 \& 3$.

\subsection{Association Between Perceived Social Support and Depression Among Study Participants}

Majority $(89.7 \%)$ of the patients with depression had a low level of perceived social support while only $0.8 \%$ had a high level of social support. A greater proportion of the patients who did not have depression were those who had moderate and high levels of Perceived social support. Perceived social support level was significantly associated with having depression; also, the mean perceived social support scores were significantly associated with depression. Table 4 . 
Table 1. Sociodemographic and clinical characteristics of study participants $(n=386)$.

\begin{tabular}{|c|c|c|}
\hline Variables & Value & \\
\hline Mean age (years) & $45 \pm 10.3$ & \\
\hline \multirow[t]{2}{*}{ Mean known duration of HIV diagnosis } & $10.4 \pm 4.0$ & \\
\hline & Frequency & Percentage \\
\hline \multicolumn{3}{|l|}{ Sex } \\
\hline Male & 87 & 22.5 \\
\hline Female & 299 & 77.5 \\
\hline \multicolumn{3}{|l|}{ Religion } \\
\hline Islam & 69 & 17.9 \\
\hline Christianity & 317 & 82.1 \\
\hline \multicolumn{3}{|l|}{ Marital status } \\
\hline Never married & 35 & 9.1 \\
\hline Married & 191 & 49.5 \\
\hline Separated & 15 & 3.9 \\
\hline Divorced & 25 & 6.5 \\
\hline Widowed & 120 & 31.0 \\
\hline \multicolumn{3}{|l|}{ Domicile } \\
\hline Urban & 265 & 68.7 \\
\hline Rural & 131 & 31.3 \\
\hline \multicolumn{3}{|l|}{ Education } \\
\hline None & 70 & 18.1 \\
\hline Primary & 97 & 25.1 \\
\hline Secondary & 107 & 27.7 \\
\hline Tertiary & 112 & 29.0 \\
\hline \multicolumn{3}{|l|}{ Employment status } \\
\hline Employed & 219 & 56.7 \\
\hline Unemployed & 167 & 43.3 \\
\hline \multicolumn{3}{|l|}{ Monthly income } \\
\hline$<\mathrm{N} 18,000$ & 263 & 68.1 \\
\hline$\geq 18,000$ & 123 & 31.9 \\
\hline \multicolumn{3}{|l|}{ ART regimen } \\
\hline \multicolumn{3}{|l|}{ First line } \\
\hline $\mathrm{TDF} / \mathrm{FTC} *(3 \mathrm{TC}) / \mathrm{EFV}$ & 147 & 38.0 \\
\hline $\mathrm{AZT} / 3 \mathrm{TC} / \mathrm{NVP}$ & 174 & 45.0 \\
\hline $\mathrm{ABC} / 3 \mathrm{TC} / \mathrm{EFV}$ & 3 & 0.8 \\
\hline $\mathrm{TDF} / 3 \mathrm{TC} / \mathrm{DTG}$ & 6 & 1.6 \\
\hline \multicolumn{3}{|l|}{ Second line } \\
\hline $\mathrm{TDF} / 3 \mathrm{TC} / \mathrm{ATV} / \mathrm{r}$ & 40 & 10.4 \\
\hline $\mathrm{TDF} / 3 \mathrm{TC} / \mathrm{LPV} / \mathrm{r}$ & 13 & 3.4 \\
\hline $\mathrm{ABC} / 3 \mathrm{TC} / \mathrm{ATV} / \mathrm{r}$ & 1 & 0.3 \\
\hline $\mathrm{AZT} / 3 \mathrm{TC} / \mathrm{ATV} / \mathrm{r}$ & 2 & 0.5 \\
\hline \multicolumn{3}{|l|}{ Most recent CD4 Cells $/ \mathrm{mm}^{3}$} \\
\hline$<500$ & 207 & 53.6 \\
\hline$\geq 500$ & 179 & 46.4 \\
\hline \multicolumn{3}{|l|}{ Most recent viral load copies $/ \mathrm{ml}$} \\
\hline$<1000$ & 355 & 92.0 \\
\hline$\geq 1000$ & 31 & 8.0 \\
\hline \multicolumn{3}{|l|}{ Adherence $\%($ mean $=94.4 \pm 13.6)$} \\
\hline$<95$ & 70 & 18.0 \\
\hline$\geq 95$ & 316 & 82.0 \\
\hline \multicolumn{3}{|l|}{ Depression Grade } \\
\hline None & 260 & 67.4 \\
\hline Mild & 104 & 26.9 \\
\hline Moderate & 16 & 4.1 \\
\hline Moderately severe & 5 & 1.3 \\
\hline Severe & 1 & 0.3 \\
\hline
\end{tabular}


Table 2. Level of perceived social support and sociodemographic characteristics $(n=386)$.

\begin{tabular}{|c|c|c|c|c|}
\hline \multirow{2}{*}{ Variable } & \multicolumn{4}{|c|}{ Level of perceived social support } \\
\hline & Low $(n=156)$ Frequency $\%$ & Moderate $(n=193)$ Frequency \% & High $(n=37)$ Frequency \% & $P$ value \\
\hline \multicolumn{5}{|c|}{ 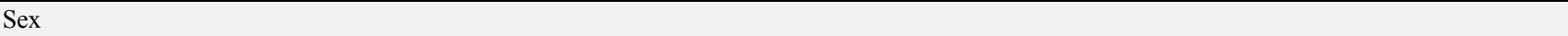 } \\
\hline Female & $133(86.5)$ & $143(73.1)$ & $23(62.2)$ & \multirow{2}{*}{0.001} \\
\hline Male & $21(13.5)$ & $52(26.9)$ & $14(37.8)$ & \\
\hline \multicolumn{5}{|c|}{ Age group (years) } \\
\hline$<45$ & $82(52.6)$ & $80(41.5)$ & $22(59.5)$ & \multirow{2}{*}{0.04} \\
\hline$\geq 45$ & $74(47.4)$ & $113(58.5)$ & $15(40.5)$ & \\
\hline \multicolumn{5}{|l|}{ Religion } \\
\hline Islam & $29(18.6)$ & $35(18.1)$ & $5(13.5)$ & \multirow{2}{*}{0.8} \\
\hline Christianity & $127(81.4)$ & $158(81.9)$ & $32(86.5)$ & \\
\hline \multicolumn{5}{|l|}{ Marital status } \\
\hline Never married & $14(8.9)$ & $17(8.8)$ & $4(10.8)$ & \multirow{5}{*}{0.10} \\
\hline Married & $66(42.3)$ & $102(52.8)$ & $23(62.2)$ & \\
\hline Separated & $7(4.5)$ & $5(2.6)$ & $3(8.1)$ & \\
\hline Divorced & $9(5.8)$ & $15(7.8)$ & $1(2.7)$ & \\
\hline Widowed & $60(38.5)$ & $54(28.0)$ & $6(16.2)$ & \\
\hline \multicolumn{5}{|l|}{ Domicile } \\
\hline Urban & $104(66.7)$ & $137(71.0)$ & $24(64.9)$ & \multirow{2}{*}{0.60} \\
\hline Rural & $52(33.3)$ & $56(29.0)$ & $13(35.1)$ & \\
\hline \multicolumn{5}{|l|}{ Education } \\
\hline None & $28(17.9)$ & $38(19.7)$ & $4(10.8)$ & \multirow{4}{*}{0.03} \\
\hline Primary & $50(32.1)$ & $41(21.2)$ & $6(16.2)$ & \\
\hline Secondary & $45(28.8)$ & $51(26.4)$ & $11(29.7)$ & \\
\hline Tertiary & $33(21.2)$ & $63(32.6)$ & $16(43.2)$ & \\
\hline \multicolumn{5}{|c|}{ Employment status } \\
\hline Employed & 77 (49.4) & $114(59.1)$ & $28(75.7)$ & \multirow{2}{*}{0.009} \\
\hline Unemployed & $79(50.6)$ & $79(40.9)$ & $9(24.3)$ & \\
\hline \multicolumn{5}{|c|}{ Monthly income } \\
\hline$<\mathrm{N} 18,000$ & $122(78.2)$ & $122(63.2)$ & $19(51.3)$ & \multirow{2}{*}{0.0008} \\
\hline$\geq \mathrm{N} 18,000$ & $34(21.7)$ & $71(36.8)$ & $18(48.7)$ & \\
\hline \multicolumn{5}{|c|}{ Known duration of HIV diagnosis } \\
\hline $1-5$ years & $27(17.3)$ & $28(14.5)$ & $6(16.2)$ & \multirow{3}{*}{$<0.00001$} \\
\hline $6-10$ years & $38(24.4)$ & $51(26.4)$ & $10(27.0)$ & \\
\hline$>10$ years & $91(58.3)$ & $114(59.1)$ & $21(56.8)$ & \\
\hline \multicolumn{5}{|c|}{ History of Support group affiliation } \\
\hline Yes & $24(15.4)$ & $31(16.1)$ & $22(59.5)$ & \multirow{2}{*}{$<0.00001$} \\
\hline No & 132 (84.6) & 164 (84.9) & $15(40.5)$ & \\
\hline \multicolumn{5}{|c|}{ Most recent CD4 (cells $\left./ \mathrm{mm}^{3}\right)$} \\
\hline$<500$ & $89(57.0)$ & $97(50.3)$ & $21(56.8)$ & 0.4 \\
\hline$\geq 500$ & $67(43.0)$ & $96(49.7)$ & $16(43.2)$ & 0.7 \\
\hline Most recent vir & (copies/ml) & & & \\
\hline$<1000$ & $141(90.4)$ & 179 (92.7) & 35 (94.6) & 06 \\
\hline$\geq 1000$ & $15(9.6)$ & $14(7.3)$ & $2(5.4)$ & 0.0 \\
\hline Adherence \% & & & & \\
\hline$<95$ & $29(18.6)$ & 37 (19.2) & $4(10.8)$ & 0.5 \\
\hline$\geq 95$ & $127(81.4)$ & $156(80.8)$ & $33(89.2)$ & 0.0 \\
\hline
\end{tabular}

Table 3. Mean Perceived social support scores and sociodemographic characteristics.

\begin{tabular}{lcc}
\hline Characteristic & Perceived Social Support score; mean \pm SD & P value \\
\hline Sex & & \\
Male & $53.2 \pm 13.6$ & 0.001 \\
Female & $47.0 \pm 14.7$ & \\
Age (years) & & \\
$<45$ & $47.5 \pm 16.0$ & 0.18 \\
$\geq 45$ & $49.5 \pm 13.3$ & \\
Religion & & 0.43 \\
Islam & $50.0 \pm 13.7$ & \\
Christianity & $48.5 \pm 14.9$ & \\
Marital Status & & \\
Never married & $48.8 \pm 15.6$ & 0.24 \\
Married & $50.2 \pm 14.5$ & \\
Separated & $46.5 \pm 22.2$ & \\
Divorced & $46.6 \pm 13.6$ & \\
widowed & $46.5 \pm 13.6$ & \\
\hline
\end{tabular}




\begin{tabular}{lcc}
\hline Characteristic & Perceived Social Support score; mean \pm SD & P value \\
\hline Domicile & & \\
Urban & $48.7 \pm 14.3$ & 0.71 \\
Rural & $48.1 \pm 15.4$ & \\
Educational Status & $47.3 \pm 14.6$ & \\
None & $45.6 \pm 14.5$ & 0.06 \\
Primary & $49.8 \pm 13.9$ & \\
Secondary & $50.6 \pm 15.3$ & \\
Tertiary & & \\
Employment Status & $50.5 \pm 14.3$ & 0.003 \\
Employed & $46.0 \pm 14.9$ & \\
Unemployed & $47.3 \pm 14.3$ & 0.015 \\
Monthly Income & $51.2 \pm 15.1$ & \\
$<$ N18,000 & & \\
$\geq$ N18,000 & $47.6 \pm 15.2$ & \\
Known duration of HIV infection & $48.4 \pm 14.1$ & 0.74 \\
1 - 5 years & $49.4 \pm 14.4$ & \\
$6-10$ years & & \\
$>10$ years & $47.4 \pm 14.4$ & 0.002 \\
History of Support Group affiliation & $53.1 \pm 14.9$ & \\
No & & \\
Yes &
\end{tabular}

Table 4. Distribution of Perceived Social Support levels and mean scores among study participants with and without depression $(n=386)$.

\begin{tabular}{lll}
\hline Variables & Depression absent PHQ-9 score $\leq \mathbf{4}(\mathbf{n}=\mathbf{2 6 0})$ & Depression present PHQ-9 score $>\mathbf{4}(\mathbf{n}=\mathbf{1 2 6})$ \\
\hline Perceived social Support & Frequency $\%$ & Frequency $\%$ \\
\hline Level & & \\
Low & $42(16.2)$ & $114(90.5)$ \\
Moderate & $182(70.0)$ & $11(8.7)$ \\
High & $36(13.8)$ & $1(0.8)$ \\
Mean score \pm SD & & \\
Low: $34.6 \pm 10.8$ & $41.5 \pm 3.6$ & $32.0 \pm 9.2$ \\
Moderate: $55.4 \pm 5.5$ & $55.5 \pm 5.5$ & $55.9 \pm 1.3$ \\
High: $71 \pm 2.6$ & $71.1 \pm 2.7$ & $70 \pm 0.01$ \\
Total: $48.5 \pm 14.7$ & $55.4 \pm 9.8$ & $34.4 \pm 12.8$ \\
\hline
\end{tabular}

\section{Discussion}

The findings of this study carried out in HIV-infected adults of an ART clinic revealed varying levels of perceived social support among the study participants as follows: low $(39.9 \%)$, moderate $(50.5 \%)$ and high $(9.6 \%)$. This showed that the majority of participants had a moderate level, and only a small percentage of them had a high level of perceived social support. With the background knowledge from the literature that perceived social support plays a protective role against mental health conditions in PLWHA, this finding of a small population with high perceived social support is a cause for concern because it translates into a lower percentage of the population benefitting from the protective effects of perceived social support $[8,12]$. This finding of $50.5 \%$ having moderate level of PSS is similar to the findings in a similar study carried out in India where $54.8 \%$ of the study population also had moderate level of perceived social support [21]. This similarity may be because both studies were conducted in developing countries where comparable socioeconomic conditions prevail.

In this study, low level of perceived social support was found to be significantly associated with certain factors which included female gender, age group $\geq 45$ years, shorter known duration of HIV diagnosis, lower educational status, lower monthly income, unemployed status and no history of affiliation with a support group. A study in the western part of Nigeria also identified lack of employment as a significant factor in low level of perceived social support [22]. This relationship between perceived social support and some of the listed factors can be attributed to the fact that in many instances, a lower level of education is more likely to result in a lower income or even unemployment and the ensuing need to rely on others for material and ultimately social support. Females are more predisposed to being less or uneducated due to cultural and societal values in this part of the world where this study was carried out, while the older age of above 45 years is associated with increased risk for other chronic diseases which result in increased demand for social support. Social support that may be provided by family friends, community and health care providers to those who are in need may not necessarily be perceived by them as useful. The absence of social support is a serious barrier to optimal clinical outcomes particularly in chronic HIV care; however the main benefits of any available social support provided ultimately depend on the receiver's perception of the support [8].

The major category of perceived social support found in this study was the moderate level. A plausible explanation for 
the widespread moderate level of perceived social support among the majority of study participants may be found in the routine ART clinic system of scheduling follow up appointments for its patients; whereby a group of patients who enrol into the ART program on the same day are likely to keep meeting regularly during subsequent follow up clinic visits because their booking patterns coincide and they inadvertently end up spending time together regularly in group counselling sessions, while waiting to be attended to for consultation, laboratory service or pharmacy pick up, and this may lead to the development of social bonds which foster social and peer support that actually become a source of enhancing perception of social support. Patients newly diagnosed and enrolling in HIV care may be more prone to low levels of perceived social support than those who have been enrolled for longer periods [23].

The majority of the patients were found to have optimal adherence percentage levels $\geq 95 \%$ and viral suppression $<$ 1000 copies $/ \mathrm{ml}$ ( $82 \%$ and $92 \%$ respectively), however less than half $(46.4 \%)$ of them had CD4 count levels $\geq 500$. No correlation was found between the perceived social support levels and these laboratory/pharmacy $\log$ indices of monitoring HIV disease, but a definite conclusion cannot be drawn from these results as the study was not designed for that purpose.

The prevalence of depression in the study participants was found to be $32.6 \%$, which is considered to be on the high side. This finding of a high prevalence is however not surprising having noted that in this group of study participants, the level of perceived social support was predominantly moderate and low levels, which would have a lower buffering effect than what would have obtained had there been a larger proportion of participants with high levels of perceived social support. This high prevalence of depression being associated with moderate levels of perceived social support is comparable to the $35.5 \%$ depression prevalence found in a similar study in India, also a developing country like Nigeria, where the majority of participants also had moderate level of social support [21]. While the index study was a hospital based study with a larger sample size, the study in India was a community based study with a smaller sample size. The larger proportion of females in this study may also be a contributory factor to the high prevalence of depression since women are more prone to depression [24-26]. In a similar Vietnamese study the depression prevalence recorded was lower (26.2\%), and though the overall social support level for the study was not stated, over $80 \%$ of the participants were documented to have been receiving social support from family, and 30-40\% from someone outside their family, all of which could have contributed to lowering the prevalence of depression [27]. The Vietnamese study was also hospital based as this current study but it was a much larger study.

The findings in this study conducted in Jos, Nigeria have also confirmed the significant association between perceived social support and depression as previously reported by studies in other geographical regions of the world $[15,16$, 27-29]. There were statistically significant differences in levels of perceived social support, as well as in the mean perceived social support scores $(\mathrm{P}=<0.00001$ and 0.000 respectively) between the study participants with depression and those without depression.

Apart from being protective against depression, perceived social support has been found to have a protective relationship with other factors that are relevant to psychosocial and mental well-being of PLWHA, some of which include: improved quality of life, coping styles, reduced risk for sexually transmitted infections/HIV transmission in females, psychological well-being [6], disclosure of HIV status [6, 12, $28,30,31]$. These factors, were not investigated in this study but are worthy of mention because of the vital role they play in the mental health of PLWHA.

\section{Conclusion}

Results of this study suggest gaps in the social support needs of the participants who are ART patients, thereby highlighting a need for interventions aimed at improving the perception of social support among these PLWHA. Further studies are needed to identify what those unmet needs are, and device strategies to address them. This would go a long way in improving their mental health and general outcomes.

\section{Limitations}

The study was cross-sectional therefore the results do not necessarily imply causality. Participants in this study were those receiving care at a standard ART clinic, so they may differ from those not receiving care or receiving substandard care. Other factors that may have had correlation with perceived social support were not assessed.

\section{Conflict of Interest}

The authors declare no conflict of interest.

\section{Acknowledgements}

The authors wish to acknowledge all the participants for their cooperation in this research, and also the APIN management for granting us permission to carry out the study and use laboratory / pharmacy data.

\section{References}

[1] UNAIDS. Global HIV \& AIDS statistics - 2018 fact sheet. Available from: https://www.hiv.gov/hivbasics/overview/data-and-trends/global-statistics. [Last accessed February 23, 2019].

[2] Rabkin JG. HIV and Depression: 2008 review and update. Curr HIV/AIDS Rep. 2008; 5 (4): 163-71.

[3] Brandt R. The mental health of people living with HIV/AIDS in Africa: a systematic review. Afr J AIDS Res. 2009; 8 (2): 123-33. 
[4] Valente SM. Depression and HIV disease. J Assoc Nurses AIDS Care. 2003; 14 (2): 41-51.

[5] WHO 2018. Depression. Available from: http://www.who.int/news-room/fact-sheets/detail/depression. [Last accessed November 17, 2018].

[6] Beka K, Shaka N. The relationship between perceived social support and psychological well-being among HIV/AIDS patients. J Edu Soc Behav Sci. 2018; 26 (3): 1-11

[7] Seeman T. Social Support. McArthur Research Network on SES \& Health. Available from: https://macses.ucsf.edu/research/prychosocial/socsupp.php [Last accessed on February 24, 2019]

[8] McDowell TL, Serovich JM. The effect of perceived and actual social support on the mental health of HIV-positive persons. AIDS Care. 2007; 19 (10): 1223-1229.

[9] Stewart RC, Umar E, Tomenson B, Creed F. Validation of the multidimentional scale of perceived social support (MSPSS) and the relationship between social support, intimate partner violence and antenatal depression in Malawi. BMC Psych. 2014; 14: 180 .

[10] Wang X, Cai L, Qian J, Peng J. Social support moderates stress effects on depression. Int J Ment Healt Sys. 2014; 8: 41.

[11] Ates B. Percieved social support and assertiveness as a predictor of psychological counselors' psychological wellbeing. Int Ed Stud. 2016; 9 (5): 28-39.

[12] Roohafza HR, Afshar H, Keshteli AH, Mohammedi N, Faizi A et al. What's the role of perceived social support and coping styles in depression and anxiety? J Res Med Sci. 2014; 19 (10): 944-949.

[13] Zimet GD, Dahlem NW, Zimet SG, Faley GK. The Multidimensional Scale of Perceived Social Support. J Per Ass. 1988; 52: 30-41.

[14] Rao D, Chen W, Pearson CR, Simoni JM, Fredriksen-Goldsen K. Nelson K. Zhao $\mathrm{H}$ et al. Social support mediates the relationship between HIV stigma and depression/quality of life among people living with HIV in Beijing, China. Int JSTD AIDS. 2012; 23 (7): 481-484.

[15] Terence CE, Sidi H, Choy KK, Mahadevan R. Prevavalence of depressive disorder and its association with percieved social support among patients with human immunodeficiency virus (HIV) in hospital Tuanku Jaafar, Seremban (HTJS), Malaysia. As J Psychiatr. 2017; 18 (1): http://www.aseanjournalofpsychiatry.org/index.php/aseanjour nalofpsychiatry/article/download/479/277.

[16] Alemu H, Haile MD, Tsui A, Ahmed S, Shewamare A. Effect of depressive symptoms and social support on weight and CD4 count increase at HIV clinic in Ethiopia. AIDS Care. 2012; 24 (7): 866-876.

[17] National Bureau of Statistics, Federal Republic of Nigeria: 2006 Population Census official Gazette FGP 71/52007/2,500 (OL24); Legal notice of the publication of the details of the breakdown of the National and State provincial totals 2006 census. Available from: https://www.nigerianstat.gov.ng/connection/pop2006pdf [Last accessed on February 24, 2019].

[18] NACA Nigeria. Nigeria HIV/AIDS Indicator and Impact Survey, national factsheet. Available at:
https://naca.gov.ng/wp-content/uploads/2019/03/NAISSNORTH-CENTRAL-ZONE-FACTSHEET_V0. 9_030719edits.pdf [Last accessed on March 23, 2019].

[19] Jekel JF, Katz DL, Elmore JG. Sample size, randomisation and probability theory. In; Epidemiology, biostatistics and preventive medicine. 2nd ed. Philadelphia, USA: W. B Saunders; 2001: 194-199.

[20] Cameron IM, Crawford JR. Lawton K, Reid IC. Psychometric comparison of PHQ-9 and HADS for measuring depression severity in primary care. Br J Gen Pract. 2008; 58 (546): 32-6.

[21] Gohain Z, Halliday M. Internalized HIV-stigma, mental health, coping and perceived social support among people living with HIV/AIDS in Aizawl district- A pilot study. Psychol. 2014; 5: 1794-1812.

[22] Folasire OF, Akinyemi O, Owoaje E. Perceived social support among HIV positive and HIV negative people in Ibadan, Nigeria. WJA. 2014; 4: 15-26.

[23] Lifson AR, Workneh S, Hailemichael A, Demmissie W, Slater L et al. Perceived social support among HIV patients newly enrolled in care in rural Ethiopia. AIDS Care. 2015; 27 (11): $1382-1386$.

[24] Chikezie UE, Otakpor AN, Kuteyi OB, James BO. Depression among people living with human immunodeficiency virus infection/acquired immunodeficiency syndrome in Benin City, Nigeria: A comparative study. Niger J Clin Pract. 2013; 16: 238-42.

[25] Mohammed M, Mengistie B, Dessie Y, Godana W. Prevalence of depression and Associated Factors among HIV Patients Seeking Treatments in ART Clinics at Harar Town, Eastern Ethiopia. J AIDS Clin Res. 2015; 6: 474.

[26] Do AN, Rosenberg ES, Sullivan PS, Beer L, Strine TW, Schulden JD, Fagan JL et al. Excess Burden of Depression among HIV-Infected Persons Receiving Medical Care in the United States: Data from the Medical Monitoring Project and the Behavioral Risk Factor Surveillance System. PLoS ONE. 2014; 9: e92842.

[27] Matsumoto S, Yamaoka K, Takahashi K, Tanuma J, Mizushima D, Duy Do C, Nguyen DT et al. Social support as a key protective factor against depression in HIV-infected patients: Report from large clinics in Hanoi, Vietnam. Sci Rep. 2017; 7 (1): 15489.

[28] Vyavaharhar M, Moneyham L, Corwin S, Tavakoli A, Saunders R, Annang L. HIV disclosure, social support and depression among HIV-infected African American women living in the rural southeastern United states. AIDS Ed Prev. 2011; 23 (1): 78-90.

[29] Shrestha S, Poudel KC, Poudel-Tandukar K, Kobayashi J, Pandey BD, Yasuoka J, Otsuka K, Jimba M. Perceived family support and depression among people living with HIV/AIDS in the Kathmandu Valley, Nepal. J Int Assoc Prov AIDS Care. 2014; 13 (3) 214-222.

[30] Yadav S. Perceived social support, hope, and quality of lifeof persons living with HIV/AIDS: a case study from Nepal. Qual Life Res. 2010; 19 (2): 157-66

[31] Ramiro MT, Teva I, Bermudez MP, Buela-Casal G. Social support, self-esteem and depression: Relationship with risk for sexually transmitted infections/HIV transmission. Int J Clin Healt Psych. 2013; 13: 181-188. 